\title{
THIRD-DEGREE BURN IN THE REGION OF THE ELECTROSURGICAL PAD DURING SHOULDER ARTHROSCOPY: A CASE REPORT
}

Leandro Cardoso Gomide', Celso Eduardo Ribeiro Gonçalves Santos', Cleber Jesus Pereira', Luiz Cláudio Coelho Carvalho', Sérgio Antônio Souza Queiroz', Roberto da Cunha Luciano', Daniel Barros Pereira², Lélia Pereira Leocádio³

\section{ABSTRACT}

The number of shoulder arthroscopy procedures is increasing and, because of this, the frequency of related complications is also increasing. This report presents a case of third-degree burn from an electrosurgical pad during this procedure and serves as an alert regarding the possible causes and how to try to prevent this rare, but possible complication.

Keywords - Burns/etiology; Burns/prevention \& Control; Equipment Failure

\section{INTRODUCTION}

Shoulder arthroscopy is an increasingly frequent procedure nowadays and, for this reason, the frequency of complications from this surgical technique is also increasing. In the present study, we report on a case of third-degree burns at the site where an electrosurgical pad was placed on a patient's thigh. We have only found one similar case in the literature.

Good comprehension of the potential mechanisms for burns among patients undergoing electrocauterization during surgical procedures is needed, in order to make these lesions as rare as possible.

\section{CASE REPORT}

A 28-year-old male volleyball player underwent arthroscopy in his right shoulder to treat a bursal partial tear of the rotator cuff, which was performed in the deckchair position. A self-adhesive $\left(3 \mathrm{M}^{\circledR}\right)$ electrosurgical pad (return conductor) on the left thigh was used for electrocoagulation.
During the arthroscopy, no joint abnormality was seen. In the subacromial space, after performing bursectomy, the partial tear of the rotator cuff was located. Only debridement was performed on it, using a shaver. After this, an ablation device for electrocauterization (Linvatec ${ }^{\circledR}$ ) was used to remove soft tissue from the lower surface of the acromion, in order to expose it better and proceed to acromioplasty. This was completed in around 10 minutes. After closure of the portals, dressings were applied and the shoulder was immobilized in a sling.

At the time of removing the surgical drapes, it was seen when removing the electrosurgical pad that a third-degree burn had occurred at the pad site (Figure 1). A plastic surgeon at our hospital was contacted to make an assessment. He recommended that it should be kept under observation for the first few days, followed by debridement of necrotic tissue as a separate procedure and then daily use of dressings containing neomycin sulfate and bacitracin. Four months later, the lesion had healed (Figure 2).

1 - Orthopedist at Hospital Orthomedcenter, Uberlândia, MG, Brazil.

2 - Head of the Orthopedics Service, Hospital Orthomedcenter, Uberlândia, MG, Brazil.

3 - Physiotherapist at Hospital Orthomedcenter, Uberlândia, MG, Brazil.

Work performed at Hospital Orthomedcenter, Uberlândia, MG.

Correspondence: Av. Rondon Pacheco 555 - Bairro Copacabana - 38400-242 - Uberlândia, MG. E-mail: leandro@orthomedcenter.com.br 


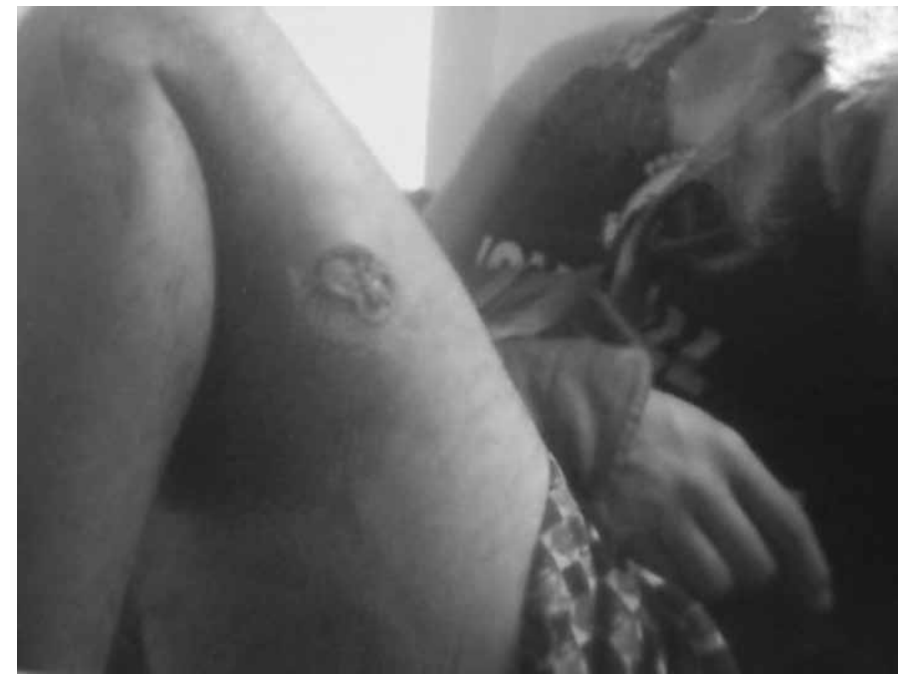

Figure 1 - Third-degree burn on the lateral face of the left thigh.

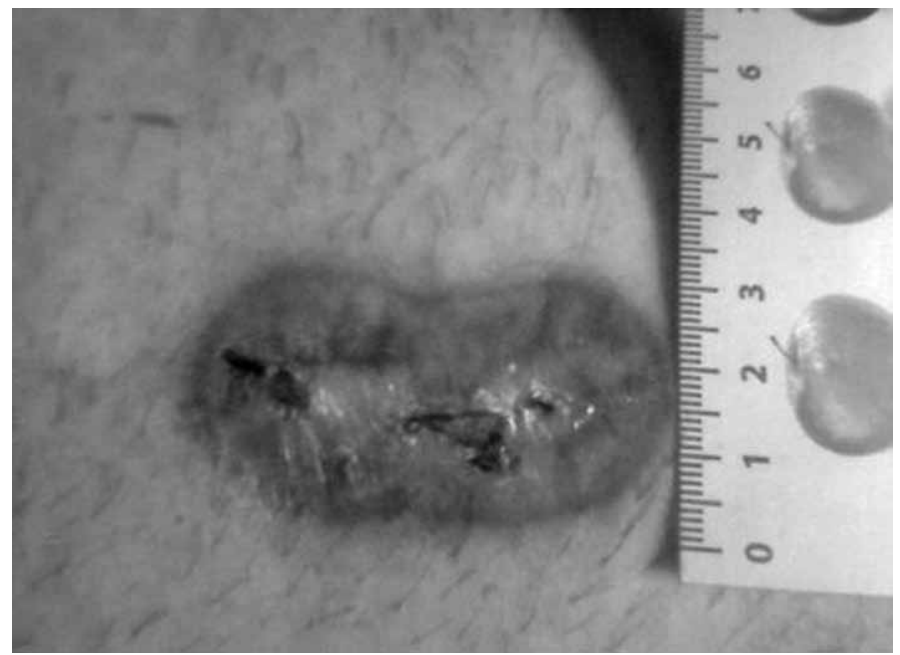

Figure 2 - Healed burn, four months later.

\section{DISCUSSION}

Shoulder arthroscopy is increasingly being used by orthopedic surgeons. It is a technique in which electrosurgical instruments are frequently used to control bleeding, or for ablation of soft tissues. Because of the heat produced, and the electric current, burns may occur on patients.

According to Mundinger et $\mathrm{al}^{(1)}$, burns due to electrocauterization during the operation can be divided into four categories: 1) burns due to direct contact, resulting from incorrect use of electrodes; 2) burns at the earth (ground) pad; 3) burns resulting from wet electrodes; 4) burns occurring outside of the operative field as a result of circuits generated between the active electrode and an alternative earth source.

Rev Bras Ortop. 2011;46(1):91-3
Basically, a traditional electrosurgical current in a monopolar circuit functions in the following manner: an electrosurgical current is produced in a generator, and this is led to the electrode through cables. This active electrode transmits the surgical current to the tissue, and the current will leave the patients through an electrosurgical earth (ground) pad and then will return to the generator. Since the surface area of the earth pad is much greater than that of the active electrode (at which the cut, coagulation or ablation takes place), the current is dispersed over a large area, thereby minimizing the heating of the tissue underneath the earth pad. However, if the current increases, the temperature of the pad will also increase. According to Fickling et al ${ }^{(2)}$, if the temperature of the earth pad exceeds $44^{\circ} \mathrm{C}$, burns may occur.

Also according to these authors, three factors contribute towards such burns. Firstly, long-duration activation of electrocauterization, especially at high temperatures would heat up the earth (ground) pad excessively. Secondly, if the contact area under the earth pad were to decrease, this would result in concentrating the current only at the remaining contact points and thus the current would not disperse across the whole area of the earth pad. This could occur for several reasons: the pad may have been placed on an area with a lot of body hair, which had not been shaved off; on bone prominences; on areas with little soft tissue; on oily areas; on areas presenting a lot of hydrating cream; or on areas with scars. Thirdly, which we also believe is likely, we used high currents for long periods of time without interruption. This was done in order to attempt to reduce the bleeding, given that the anesthetist was not managing to achieve adequate hypotension for the procedure. A cerebral lesion due to low flow was therefore feared, given that the patient was being operated in the deckchair position.

Another reason for the bleeding was that in shoulder arthroscopy no pneumatic tourniquet is used, thus differing from arthroscopy on the knee and ankle. Moreover, an additional reason for using high currents was that physiological serum is used in arthroscopy. This solution conducts electricity and gives rise to dispersion of the electric current outside of the desired surgical site, thus making it necessary to use higher currents to have the desired effect. 
Another topic that deserves to be discussed is that for the surgery on our patient, not only was plexus block applied, but also general anesthesia. Hence, the patient became unconscious and was unable to "advise" us that he was being burnt. In other words, we were burning the patient without knowing that this was happening and we would only find out about this when the pad was removed.

Sanders et $\mathrm{al}^{(3)}$ reported that they noticed a burning smell during arthroscopy and therefore temporarily halted the procedure. In our case, we did not sense any such smell.

Burns at electrosurgical pads are extremely rare, and we believe that they are underreported in the lite- rature. It is very important to take all the precautions necessary for avoiding this complication. Sanders et $\mathrm{al}^{(3)}$ suggested that every pad that is to be used should be inspected; the pad should be placed at an appropriate, well-prepared location with a lot of muscle mass; the minimum current necessary should be used, and with pauses in order to cool down the tissue underneath the pad; and two appropriate pads should be used in high-risk patients such as children or elderly people with little muscle mass.

In addition to medical and legal consequences, burns at electrosurgical pads may have physical, financial and psychological impacts on patients and their families.

\section{REFERENCES}

1. Mundinger GS, Rozen SM, Carson B, Greenberg RS, Redett RJ. Case report: Full-thickness forehead burn over indwelling titanium hardware resulting from an aberrant intraoperative electrocautery circuit. Eplasty. 2007;8:e1.
2. Fickling $\mathrm{J}$, Loeffler $\mathrm{C}$. When is it necessary to use two patient return electrodes? Clin Information Hotline News. 2005;10(1):1-3.

3. Sanders SM, Krowka S, Giacobbe A, Bisson LJ. Case report: third-degree burn from a grounding pad during arthroscopy. Arthroscopy. 2009;25(10):1193-7. 